\title{
A study on risk perception and risk identification in the internationalization process of Chinese hi-tech enterprises -A case study of Huawei Technologies
}

\author{
(C) Higher Education Press and Springer-Verlag 2008
}

\begin{abstract}
This paper constructs an integrated model of international risk perception, and then conducts a pattern match to the model through a descriptive case study of Huawei. Huawei's internationalization process is divided into three stages, namely challenging initial exploration, horizontal expansion and all-round expansion. The key risks and prevention measures at each stage are observed on the macroscopic level, industrial level and corporate level respectively, and the model base on an analysis of Huawei's risk perception and prevention effort is tested. Implications and suggestions are discussed with regard to the management of internationalization risks for hi-tech enterprises.
\end{abstract}

Keywords hi-tech enterprise, international operation, risk perception, descriptive case study

摘要 构建企业国际化进入程度与一体化风险感知的整合模型, 通过描述性案例研 究对模型进行模式匹配分析。以华为技术有限公司国际化进程为研究主线, 将其国 际化进程分为艰难探索、横向拓展和纵横延伸 3 个阶段, 并对各个阶段的关键风险 及其防范进行观察, 通过基于风险感知与防范的案例分析对模型进行检验, 并得出 促进高新技术企业国际化风险管理的启示。

关键词 高新技术企业, 国际化经营, 风险感知, 描述性案例研究

Received January 8, 2008

XU Hui ( $₫)$, WAN Yiqian, PEI Degui

Business school, Nankai University, Tianjin 300071, China

E-mail: susan_xuhui@126.com 


\section{Introduction}

In a global economy, enterprises implementing internationalization strategy operate in a more competitive environment with greater uncertainties and risks. They are facing international risks from such aspects as natural environment, government policy, market competition, cultural difference, etc. Because of the diversity and complexity of risk sources and its influence, the international enterprise's administrators must discern, take precautions against and control the key risks in view of the strategic policy of enterprise's internationalization, in order to reduce potential losses and promote enterprise's internationalization performance effectively.

As early as the middle of 1970 s, the progressive internationalization theory put forward by some North European scholars (Carlson, 1975) referred to the influence of international risk on internationalization. The theory agrees that, after managing the internationalization, the enterprises will adjust the strategic policy of entering the international market gradually under a predictable trend, and will strengthen the control on overseas operation when making the entry mode. Enterprises, prone to obtain greater market power must input more resources into the overseas market, thus facing greater risk. Along with the exploitation of overseas market and the intensifying of competitiveness, enterprises improve their risk control ability constantly at the same time (Chu and Anderson, 1992). Obviously, enterprises engaged in internationalization will encounter the challenge of different risks inevitably. The final winners must have adjusted their decisions progressively, and during the internationalization process they obtain deeper understanding of risk perception and improve their ability of risk avoidance.

In this study, we attempt to find out answers for the following questions: which risks will enterprises face while operating their internationalization strategy? How should enterprises take into precautions and dissolve the risk systematically in such an environment? During the exploration to these questions, we find the international risks are intricate and interconnected. If we limit our study on one or several kinds of risks, it will be too one-sided for the analysis and measurement of the risk and can hardly form an intact international risk perception system; Moreover, the limited vision may cause the study framework inoperated, due to the lack of the understanding on the characteristic of the internationalization under an uncertain environment. So, this paper chooses Huawei Technologies as a typical case to analyze the risk perception and prevention mechanisms of Chinese telecommunication equipment manufacturers during the course of their internationalization process through a case study. We chooses Huawei Technologies mainly due to the following two reasons: First, the 
manufacturing industry of the telecommunication equipment is a technology industry with high added value, high entry barrier of heavy investments, and high technology. The expansion and internationalization of this industry hence represent the direction of development of hi-tech industries; Second, an investigation of 569 international marketing and commercial experts given by Interbrand (entrusted by Business Weekly ) shows Huawei Technologies has already become a widely recognized brand and the most promising Chinese brand to achieve internationalization in this trade. Study on such a successful enterprise can get better enlightenment and be consistent with the key case demand in a single case study.

\section{Literature review and study basis}

\subsection{Literature review}

After the progressive internationalization theory, in the mid-1980s and later, scholars confirmed a comparatively clear direction and thinking in understanding international risks on the basis of transaction cost theory. The researchers believed, the transaction cost influent share volume of overseas investment, and the influencing factors include external uncertainty (Gatignon and Anderson, 1988, Kogut and Singh 1988) and inside uncertainty (Beamish 1987). The various kinds of uncertainty were defined as the source of the international risk (Beamish and Banks, 1987). Thereafter in the International Production Compromise Theory field, Dunning (1988) also referred to such factors as the investment risk, etc., when studied the factors influencing the international market entry mode. Then Kim and Hwang (1992) proposed that environmental variables and trade variables influence the international market entry mode selection. The environmental variables are the initial form of the risks. They thought the environmental variable can be subdivided into four kinds further: risk of host country, unfamiliar with area, demand uncertainty and intensity of competition.

Miller divided the internationalization uncertainty into three big classes from the perspective of executives' perception in 1992: General environmental uncertainty, industrial uncertainty and corporate uncertainty. His research formatted the uncertainties into an integrated risk management framework finally. Miller's research did an overall and systematic classification of uncertainties enterprises faced when entering the international market for the first time, the integrated framework proposed (Perceived Environmental Uncertainty, is abbreviated as PEU model) has offered a very good guideline for the study on international risks. Miller (1993) has also designed the assessment method of 
PEU in his further research, thus enable the company to evaluate the environmental risk when doing business in different countries.

Afterwards, Brouthers (1995) examined the integrated international risk model put forward by Miller empirically and constructed a framework analyzing the strategic international risk. Brouthers divided the strategic risk into two classes, namely management control risk and market complexity risk. In 1996, Keith D. Brouthers, Lance Eliot Brouther and Steve Werner continued to modify Miller's PEU, the risk is divided into six aspects: (1) the uncertainty of government policy, (2) macroeconomic uncertainty (3) the uncertainty of corporate resources and services (4) the uncertainty of demand for products, (5) competitive uncertainties, (6) industry technical uncertainty. The author named the refined evaluation method PEU2.

In sum, we find that although former researchers have studied several problems about the international risk in their discussion of international market entry strategy, they fail to study international risks as a whole. In addition, former papers failed to prove the interaction between risk perception and the international market entry strategy and provided only some incomplete explanations and conclusions. As for research approaches, former researches usually adopted the big-sample analysis to examine the theory of international risks. As a result, these papers stressed only generality while neglecting the exploration of the concrete internationalized behaviors of some enterprises. Moreover, they failed to take a microscopically close look at the behavior of representative enterprises based on international risk decision. In contrast, the case study approach regards the research object as a system and probes into the causality in the system through accurate observation and deep discussion. These virtues make case study a good supplement to the limitation of the big-sample analysis. By analyzing the risk management practice of the single enterprise's internationalization deeply, research adopting the case study approach can thus propose more operable management suggestions. On the other hand, by the look of research contents, foreign researches have already constructed the framework of risk measure from the macroscopic or the foreign trade perspective. These researches, however, were mainly based on the samples of foreign enterprises and lacked the understanding of China's specific environmental adaptability. Consequently, the applicability of domestic research conclusions concerning the internationalized behaviors of Chinese enterprises based on the framework of foreign theory is quite limited. It is necessary to analyze the practice backgrounds of Chinese enterprises thoroughly, so as to prove and perfect the suitability of the theory through case study (Zhang, 2006). 


\subsection{Conceptual framework and methods}

On the basis of relevant understanding of the integrated risk perception and risk classification, this research expands Miller's international risk perception model(1996), draws lessons from Root's research on decision of international market entry strategy (1994), and then constructs an integrated international risk perception model (Xu, 2006, as Fig. 1). As shown in the model, the macroscopic environmental risk includes political risk, policy risk, macroeconomic risk, culture risk; the industrial risk includes competition risk, product market risk, technology risk, and corporate risk includes decision risk, investment risk, financing risk, operation risk, human resources risk, community responsibility risk. Under the framework, this paper will take progressive internationalization theory as another theory basis to analyze various kinds of risks that Huawei Technologies (Huawei for short) faces at different internationalization stages systematically.

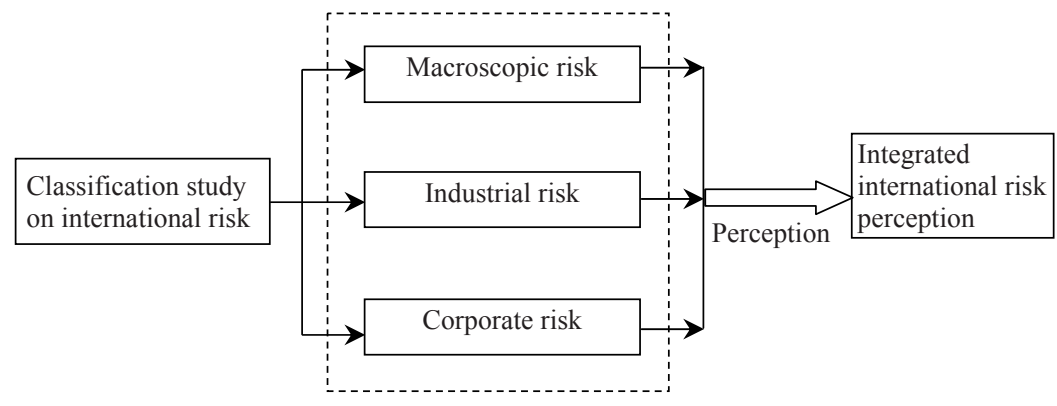

Fig. 1 The integrated international risk perception model

This paper takes the usual steps of a case study: Put forward the question-confirm the proposition of the study-clarify the analysis unit-materials and proposition binding-discussion. This paper is organized as follows: Research questions are put forward first: what risks will enterprises face in the course of internationalization? How do enterprises perceive, discern and take precautions against the risk systematically? Then we confirm the proposition studied: whether enterprises' international risk perception follows the model developed in this paper? After that we clarify the analysis unit: internationalization process of Huawei. Then we match the materials and proposition and analyze the validity of the model. Finally, managerial applications and suggestions are discussed.

Case study adopts the research approach of pattern matching and time series analysis and takes time (internationalization process) as the main clue to examine the integrated model. Two embedded analysis units, namely time and risk level 
are introduced to increase the depth of our case study.

Information and data collection are the most difficult part for up to now no book or research paper has been approved by Huawei itself. Huawei's CEO Ren Zhengfei once said that he is not intended to turn the so-called Huawei experiences into any published work ( $\mathrm{Wu}, 2006)$. To solve the problem, this case study mainly adopted three data-collecting methods: industrial data collection, follow-up research and interview. Hopefully, diversified data-collecting methods and study approaches can make the research foundation more solid and effective (Yin, 1989). Through visiting experts in the telecommunication equipment manufacturing industry and professional websites, for instance the website of Ministry of Information Industry and DRCnet, we got the basic data of telecommunications equipment manufacturers, which helped us define the industrial background and status of Huawei. In the follow-up research, the authors have paid close attention to Huawei since 2006. At first, the authors searched public publication related to Huawei. Five books were chosen, namely Go out of Chaos, Go out of Huawei, The truth of Huawei, The world of Huawei, Four faces of Huawei - Overseas founder analyses Huawei in its internationalization. The authors of these books analyzed Huawei from different perspectives. A synthesization of their researches helps us to analyze Huawei's history and current situation more objectively. Second, the authors used "Huawei", "Huawei Technologies" and "internationalization" as keywords to search for information in CNKI and China Info-bank. There are 69 research papers concerning the internationalization of Huawei, and 642 pieces of articles or reports about Huawei since 1995. Through carrying on content analysis to the materials of indirect observation, we clarified the internationalization development course and risk environment of Huawei. In addition, we conducted deep interview with 10 workers in Huawei (mainly MBA students, 7 were middle level managers or above and the rest were technicians) to confirm the authenticity of the materials we had collected from indirect observation, and to know more of the history and current situation of Huawei's internationalization from an insider's point of view. By doing so, we collected data of Huawei form external industrial information, researcher observation and interior employees, which is in consistent with the requirement of the Triangulation law and promotes the reliability of the case study.

\section{Industrial backgrounds}

Since the beginning of 1990s, China telecommunications equipment manufacturing industry has gone through the course of "technology import and digest", "technology imitation" and "technology self-innovation". From 1996, 
domestic telecommunication equipment manufacturers, with Huawei, ZTE, Fiberhome Networks, DaTang as outstanding representatives, have already set foot on expanding the overseas market. After several years of development, these Chinese enterprises have gradually become active in international telecommunications equipment market.

Huawei Technologies was established in Shenzhen in 1988. In 1994, it launched C\&C08 Digital SPC Switch, and signed a contract with Hutchison Whampoa Limited to enter the Hong Kong market. Thanks to the contract, Huawei's sales amounted to 200 million yuan in the year. After that, Huawei entered a stage of rapid development and its sales volume reached 10 billion yuan in 1999, then 20 billion yuan in 2000. In 1998, Huawei entered the rank of Top 100 electronic enterprises in China, ranked No.7 in terms of sales volumes and No.1 in terms of profit margins. Since then, Huawei has become China's most influential telecom equipment manufacturers. In 2000, the contract sales amount of Huawei was over 2.65 billion dollars, among them the overseas sales amount was over 100 million dollars. Though from 2001 to 2002, the infrastructure investment of global telecommunications dropped by $50 \%$, Huawei's international sales still increased by 68 percent, rising from 328 million dollars to 552 million dollars. At present, Huawei's products and solutions are deployed in over 100 countries and serve over one billion users worldwide. The international market has already become Huawei's main sources of sale. In 2007, $72 \%$ of Huawei contract sales were from the international market, and the company has set up 8 regional departments, more than 100 branch offices around the world. Also, they have established twelve R\&D centers around the world such as in the Silicon Valley and Dallas of the United States, Bangalore in India, Stockholm in Sweden and Moscow in Russia to ensure global R\&D with outstanding people. In addition, they have 28 training centers worldwide to help the customers and local people to study advanced management, technologies and so on. Huawei firmly believes in localizing its global operations and makes great effort to hire local talents.

Data mentioned above accurately describes Huawei's growth course and internationalization. We can see that at the beginning, Huawei was only a private-owned hi-tech agent company by some Hong Kong enterprises. Then Huawei gradually built up it own product portfolios, including mobile network, broadband network, IP-based, optical network, telecom value-added service, and terminal. Now Huawei can provide competitive communication solutions and services for customers and is one of the main suppliers of telecommunication equipment in Chinese market. Moreover, Huawei has already succeeded in entering the global telecommunication market and has realized internationalization. 


\section{Case analyses - Internationalization of Huawei: Advance along with the risk}

As stated, when measured by statistics, Huawei has made immense success. Simple figures, however, can hardly reflect the hardships Huawei faced during its course of internalization. This paper will analyze in detail the key risks Huawei face and how Huawei prevented them from happening on its internationalization way.

According to the progressive internationalization theory, enterprises engaged in internationalization generally experience several stages of evolution that: (1)irregular export; (2)utilize the independent sales representative or agent to export; (3)set up selling branch; (4)set up production or manufacturing plant (Root, 1994). The reason hi-tech enterprises are different from other manufacturing companies is that they do not need to carry on extensive production, and their achievements mainly depends on the technology and sale. Some hi-tech enterprises even need to carry out internationalization strategy by birth (Reid, 2005). As a typical representative, Huawei's internationalization course accords with the progressive internationalization theory (it adopted the above-mentioned entry modes), with unique characteristics of itself(used several kinds of entry modes synthetically and simultaneously). As a hi-tech enterprise from developing countries, when we separate Huawei's internationalization stages, we should not only consider the entry mode, but also the change in technology and the region it enters. Therefore, this research constructs a comprehensive framework for risk perception and prevention based on integrated risk perception theory and progressive theory (As shown in Fig. 2). Analysis in the rest of this paper also follows these two embedded analysis units.

This paper divides internationalization process of Huawei into three stages: difficult exploration, horizontal expansion, and all-round expansion. We firstly describe each of these three stages respectively, scanning the risks faced by Huawei. Then, in accordance with the integrated international risk perception model, we identify the key risks at each stage from the macroscopic, industrial and corporate levels, respectively. Finally, we attempt to clarify Huawei's countermeasures against these key risks. Throughout the data collecting and proposition developing processes, the authors try hard to observe and analyze as objective as possible, as objectiveness is the crux of case study. 


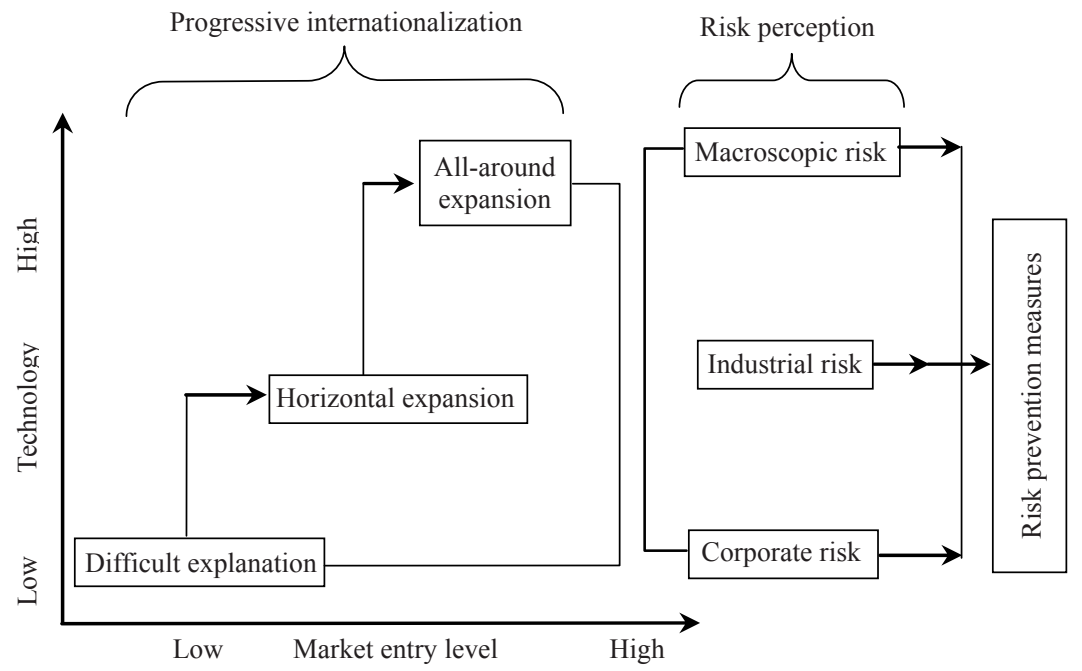

Fig. 2 The model of Huawei's risk perception and prevention

\subsection{Stage 1 (1996-1999): Difficult exploration}

\subsubsection{Risk scan}

In 1996, Huawei started the globalization strategy. But foreign countries and their customers, culture and environment were all strange to Huawei. The mean age of the staff in Huawei was only twenty seven. Most of them had no oversea experiences at all in that time. On the other hand, many countries in the world did not know China well either, not to mention a small Chinese company like Huawei. Under such circumstances, Huawei chose such friendly countries as Yugoslavia, Russia, Brazil, South Africa, Ethiopia, etc as a preliminary step of exploiting the international market. However, after marketing personnel reached these countries they did not know where the customers were. They needed half a year to solve the problem of surviving, and then found out customer's information slowly. To enlarge Huawei's reputation in these countries, sales personnels made tenders and send them to customers, expecting customers would have a basic impression of Huawei through reading the tenders. In 1996, Xu Zhijun (Huawei's vice-president) was sent to Russia to exploit the market there. In the first two weeks, he met potential cooperative partners or supportive organizations. But Russians did not believe a Chinese company can make a exchanger, they sat down and continued to listen to Xu's introduction until $\mathrm{Xu}$ put the board of circuit and chip of a switch in front them. Finally, the switches 
made by Huawei succeeded in entering Russia, thanks to the tireless efforts of the sales force. In August, 1999, Huawei realized an initial breakthrough in the international market at last-It officially won a bid in Yemen and Laos.

\subsubsection{The key risk perception}

\section{(1) Macroscopic risk}

At the first stage of internationalization process, Huawei exploited market and came to realize brand's value mainly through its irregular export and efforts of overseas marketing personnel. According to our analysis frame, the macroscopic risk was not the key risk influencing enterprise's management at this stage: since Chinese enterprises did not enter international market on a large scale, there was no need to worry about the income and asset of Chinese companies' oversea subsidiaries would be confiscated by host countries due to political reasons. Also, because of low resource commitment, the impact of the policy change in host country on enterprise was relatively small. Finally, there was no risk in both value and tradition for countries all over the world was eager to develop their telecommunication industries at that time and the manufacturing of telecommunication equipments was far from being standardized.

(2) Industrial risk

At the industrial level, risks faced by Huawei mainly came from the competition and technology changes. On the one hand, because there were such large-scale multi-national corporations as Cisco, Alcatel, etc. in the international telecommunication market, they monopolized most markets and had absolute competition advantages. Moreover, the secret of market competition in the telecommunication equipment manufacturing industry lied in the advancement of technology. Once technology development fell behind rivals, enterprise would soon be kicked out from the market. Fortunately, because Huawei was at the starting stage of its internationalization, multi-national corporations failed to detect the potential threats from Huawei. In addition, Huawei chose those comparatively more backward countries so that it could avoid competing directly with the multinational corporations. Accordingly, the risk at the industrial level was relatively small and was not the key risk.

(3) Corporate risk

The biggest risk at this stage Huawei confronted with comes from the inside of the enterprise, namely decision-making risk, operation risk and human resources risk. First, when making decisions, the company must choose the specific internationalization tactics, such as the entry of the market segment and the products positioning, etc. The formulation of decision at the starting stage of internationalization was especially important for it directly determined the future of a company's internationalization. Second, the overseas market exploration 
depended on coordination among various departments, the implementation of marketing strategy, and the effectiveness of communication and service. Third, at this stage, human resources risk was the most serious risk confronted by Huawei. Huawei needed to motivate its marketing personnel effectively so as to survive in a highly competitive market environment.

\subsubsection{Risk prevention measures}

During the internationalization exploration and the follow-up development, Huawei successfully occupied the first-class market with second-rate technology, because it adopted the correct tactics to avoid and prevent the key risks.

In the aspect of internationalization operation decision, Huawei chose suitable market, suitable opportunity and suitable entry mode to evade the political, policy and market risks. Huawei adopted Mao Zedong's strategy of "besiege the cities from the rural areas" and chose the countries where the western multinational companies did not set foot in. In doing so, Huawei started with the comparatively backward market and gradually spread out its sales network. Huawei first entered such countries with enormous market volume but weaker competition as Russia or the countries in Africa and South America, etc. At first, telecommunication industries in these nations were relatively undeveloped, the threshold of entering in technology was relatively low, and there were less technological barriers. For example, the opportunity of entering Russia market was selected when China and Russia signed the contract of "equality and mutual trust, strategic partnership relation facing up with the $21^{\text {st }}$ century", so that it obtained the greatest market influence in Russia with the minimum cost.

In the aspect of the operation management, Huawei cooperated with internationally famous companies. For example, Hay Group helped Huawei improve its human resources management and established the system of organizational positions in 1997. In 1998, IBM tailored an ISC procedure for Huawei. Accordingly, Huawei carried out a corresponding adjustment to the organization, and merged the original product departments, planning department, purchasing department, Import\&Export Department, authentication department, cooperative department, delivering department, storing department into a new supply chain management department to ensure it can find cheap, high quality, and high speed suppliers. For this reason, the foreign counterpart appraised Huawei as "Design House + Marketing Team" for its high operation efficiency.

As to the human resources risk at the difficult exploration stage, Huawei needed the unique corporate culture to consolidate strength and keep the company work at a high speed. The most remarkable culture in Huawei is "The nature of wolf". The three kinds of characteristics of the wolf are: sharp sense of smell, aggressiveness, and team spirit. Huawei makes sure its employees 
understand its culture and work with high efficiency under any tough environment. In 1995, Huawei established the famous "Huawei Basic Law", which engraves "teamwork, contribution, study, innovation, and fairness" deeply into every employee in Huawei. Except for culture edification, Huawei also carried out a series of structure adjustments. Since 1998, Hay Group has checked the improvement of Huawei in human resources management every year to find out the existing problems. Because of all these constant improvements on human resources management practice, Huawei successfully builds up a devoted sales team, which helps Huawei achieve unforgettable market success within a short time(see Fig. 3).

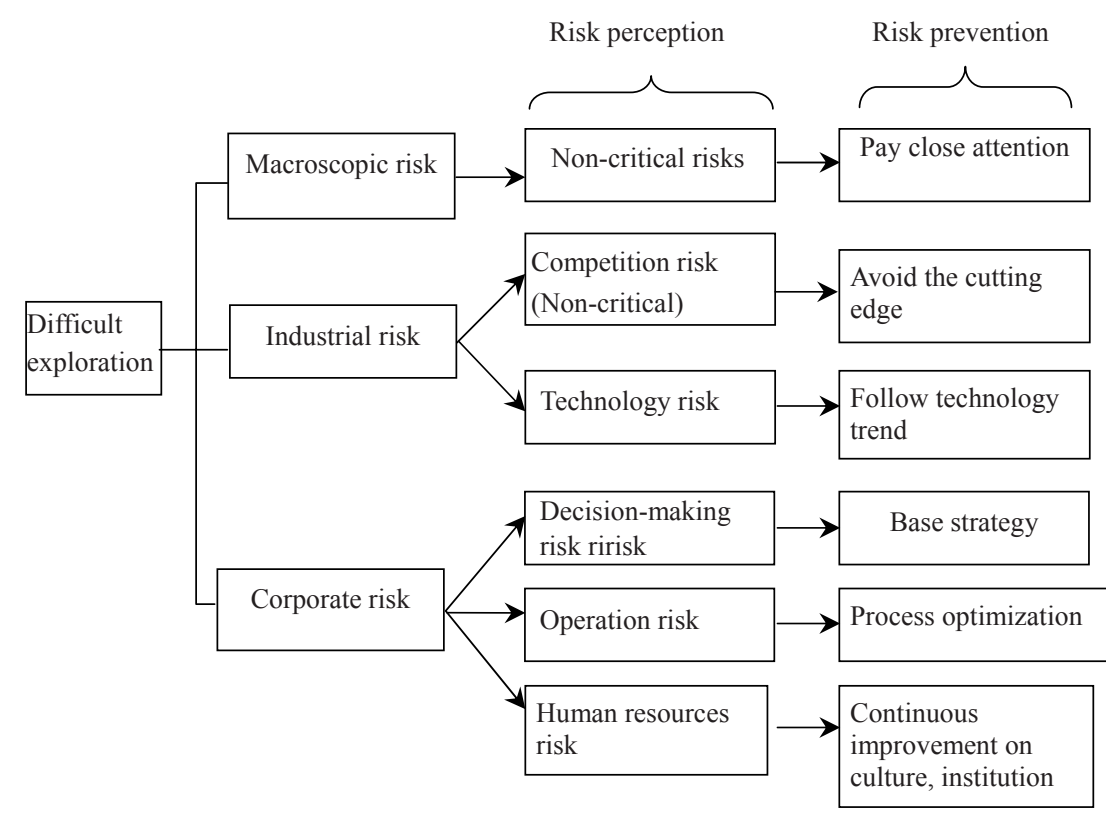

Fig. 3 Risk perception and prevention at the stage of "Difficult exploration"

\subsection{Stage 2 (1999-2001): Horizontal expansion}

\subsubsection{Risk scan}

After the initial break-through in marketing, Huawei strengthened the expansion in the international market. At this stage, Huawei concentrated its goal of overseas market on some countries with a large number of populations and thought it would find great telecommunication demand in these countries. But later, Huawai found quite a lot of nations knew very little of the modern China, which made Huawei's development in these countries very difficult. Having no 
other choices, Huawei invited its customers to China, visited China and Huawei, showed them the brilliant achievement made by Chinese people after the Reform and Opening-Up, as well as Huawei's progress in hi-tech technologies. To further develop markets in the overseas market, Huawei made a plan called "new Silk Road", by which Huawei's clients were invited to visit Beijing, Shanghai, Shenzhen, Hong Kong, and other big Chinese cities and feel the advanced manufacturing level of Huawei in these cities; Second, Huawei printed two albums of "Huawei in China" and "Huawei around the world", and hand them out to its customers from every nation. In addition, Huawei actively participated in various kinds of international exhibitions in order to deepen the understanding of Huawei for people all over the world. In 2000, Huawei invested a record high of two hundred million Hong Kong dollars to hold an international telecommunication exhibition in Hong Kong and invite nearly 2000 customers and cooperative partners to participate in this exhibition. Through all these hard work from 1999 to 2001, Huawei at last broke the ice in the international market and established its international reputation. Accordingly, the international department was divided into eight regional departments, with a total working staff nearly 1000 people. In addition, Huawei established an international marketing committee, applied a flat management mode of matrix structure, and sent company's managing vice-president, senior vice-president to each regional department. In doing so, the decision-making power was transferred to each regional headquarters. In 2001, Huawei's oversea sales volume exceeded more than 300 million dollars. Huawei succeeded in spreading its business to the markets of various countries of Asia, Africa and Latin America and seized a large segment of market shares in these countries by adopting low price strategy. In addition, Huawei set up many research centers in some developed countries to continuously advance its telecommunication technologies.

\subsubsection{The key risk perception}

(1) Macroscopic risk

The risks faced at this stage are different from those of the previous stage. Political risk and culture risk gradually become more prominent. Because Huawei sets up sales department in every overseas subsidiary and builds up its own sale and technical support platform, Huawei's resource commitment to the oversea market is greatly strengthened. Accordingly, the political risk faced by Huawei at this stage also increases. For example, the civil war and kidnappings in some African countries all exert negative influence on Huawei internationalization. In another case, ZTE, one of Huawei's rivals, won a contract to build a telecommunication network in Romania, but end up in nothing because of political turbulence in the host country. At the same time, Huawei faces 
cultural conflict too, which can be divided into two aspects: First, the conflict of the culture between China and host country; Second, the cultural conflict among Huawei's staff of different countries inside the enterprise. The harm of the culture conflict to Huawei is obvious: on the one hand, ignoring the cultural conflict between Huawei and the host countries, customer satisfaction would drop dramatically and Huawei would be unable to realize its sales goal in these countries; on the other hand, if it does not solve the cultural conflicts among its own stall, operation efficiency of Huawei would be affected negatively.

(2) Industrial risk

risks at the industrial level are mainly comprised of competition risk and technology risk. After Huawei has established its reputation, other international telecommunication equipment manufacturing giants may take various kinds of measures to restrain Huawei's development or may even try to drive Huawei away from the industry. As above, technology is the base for telecommunication equipment manufacturers to survive. If Huawei wants to continuously expand its market share internationally, it can not depend only on the second-class technology as it did at the first stage. Instead, Huawei must follow technology trend closely, carry on innovation constantly on the basis of imitation.

(3) Corporate risk

The capital operation risk arising from investment and financing and human resources risk become the key risks at the corporate level. Large-scale overseas expansion, setting up the branches, huge expense on technological development and human resources incentive made enterprises engaged in fast internationalization like Huawei suffer "The thirsty disease for capital". How to guarantee the steady operation of the capital chain becomes the major issue of vital importance to the enterprise. Corresponding to technological risk, the human resource risk is outstanding too at this stage. Huawei not only needs its sales teams to continuously exploit international market, but also relies on its technical staff to consecutively advance its technologies. Under such circumstances, the brain drain of technical experts brings great loss to Huawei, such as the case of Li Yinan's leaving.

\subsubsection{Risk prevention measures}

When tackling macroscopic risks, Huawei chose traditional friendly countries and hired local workers from the host country to finish various projects, while the Chinese workers were only responsible for management and marketing. Huawei also asked local security department offered protection and kept in close touch with China embassy in host country to evade the political risks. In the management of cultural conflict, Huawei made great efforts to realize cross-cultural coordination, promote outstanding host country's employees to 
administrative positions. In addition, Huawei unified the staff's understanding under different culture background by utilizing the company goal and corporate culture to solve possible internal cultural conflicts. The vision of Huawei is "to enrich life through communication". The mission is "to focus on customers' desire and needs by providing competitive communications network solutions and services so as to consistently create maximum value for customers".

When confronted with competition risk, Huawei adopted the commonly used comparative strategies of Chinese enterprises in the international market competition, namely cost leadership and the service competitive tactics. Because Huawei's human resources cost are relatively lower than foreign enterprises and its efficient operation, Huawei's market share in the target countries kept increasing. As to the technology risk, Huawei invested more than $10 \%$ of its revenue in R\&D. In order to speed up its technology innovation, Huawei set up a research centre in Bangalore in 1999, which passed the CMM4 assessment in 2001. In 2000, Huawei set up another two research centers in Silicon Valley and Dallas. In these overseas research centers, Huawei employees gain access to advanced technology and strengthen the cooperation with advanced technology owners. For example, Indians are good at software development and project management and Chinese staff are good at the system design and system structure. Therefore, a lot of Huawei's projects were undertaken by Chinese and Indian software programmers together. After returning to the homeland, these technical staffs with oversea experiences always become the backbone of Huawei's software development and management. To Huawei, this is not merely a way to reduce its distances with the technology front, but also a kind of effective way to train its technical personnel.

Huawei took two measures to deal with capital risk: first, lower costs through procedure optimization, maximize its profit margin, and maintain a good cash flow. In 2000, Huawei's sales volume was over 15 billion RMB. Pretax profit was all about 3 billion RMB yuan and Huawei had a high money returned rate of more than $80 \%$. On the other hand, the enterprise established good relationship with the government and banks. For this reason, Huawei got much government policy support, regardless of its private-owned background. In 1996, Vice-premier Zhu Rongji inspected Huawei and required government at different levels should support Huawei's development actively, as well as other private-owned enterprises like Huawei. Because of its good credit and swift development, Huawei became a "high-quality customer" that numerous Chinese and foreign banks strive for. As a result, Huawei got all kinds of loans from banks with more favorable conditions.

Huawei's human resource strategic planning also played an important role in preventing human resource risk at this stage. Since 1998, Huawei has launched 
an annual extensive recruitment plan to attract more talented people to join Huawei. In 2001, Huawei went to the national famous universities to recruit the most outstanding graduates. In order to retain staff, Huawei offered nearly the highest salary in all companies in Shenzhen. In addition, Huawei established a qualification management department to form a "human resource pool" and to systematically and carefully plan its human resources. In each fiscal year, after the annual sales objectives are assigned, Huawei would analyze and confirm the demands of all kinds of talents, then it would put desired talents into "the resource pool" and train these employees systematically. When a post is open, a suitable candidate would be picked up from the resource pool and assigned to the post in time. In doing so, Huawei ensured a continuous operation of the enterprise. It also stores many outstanding backup talents for its international expansion.

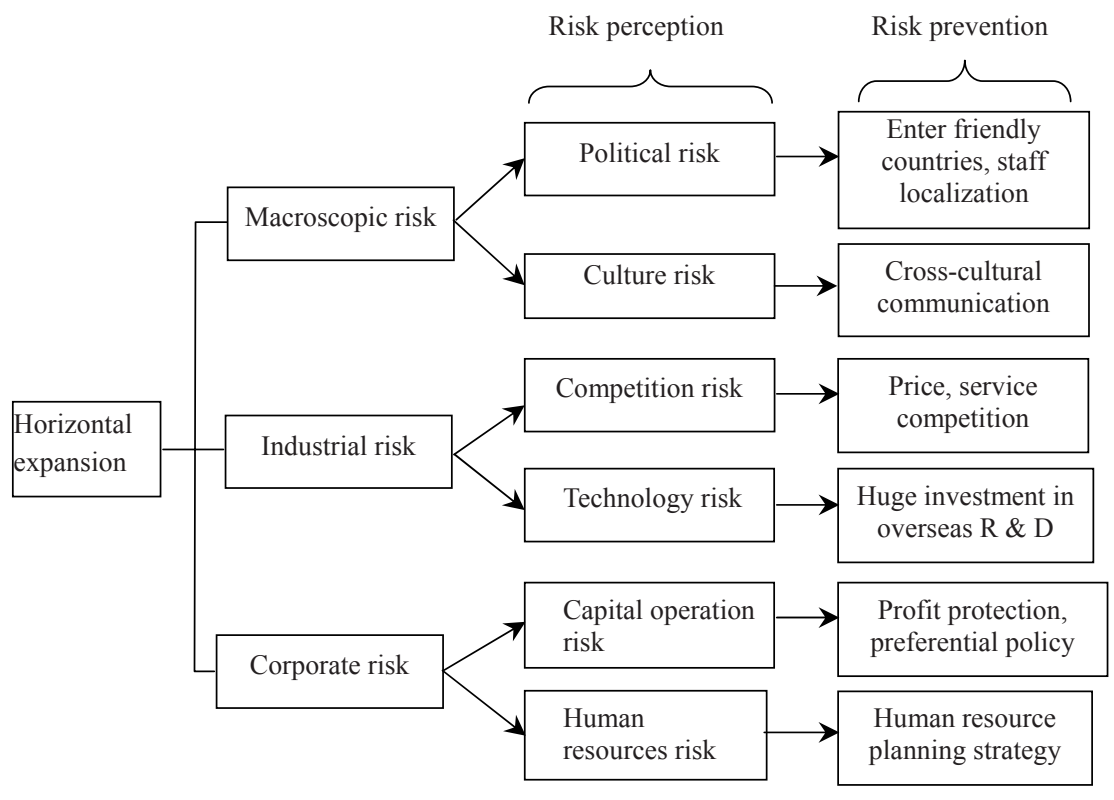

Fig. 4 Risk perception and prevention at the stage of "Horizontal expansion"

\subsection{Stage 3 (after 2001): All-round expansion}

\subsubsection{Risk scan}

After a few years of development and market exploitation, except American and European markets, Huawei's products entered and were widely accepted in other countries all over the world. Huawei also gained a widespread reputation in the 
international market. At this moment, Huawei determined to enter the American and European markets, for the markets in these two regions accounts for more than $40 \%$ of global telecommunication market. They were the traditional domain of western telecommunication giants. Though Huawei confronted quite a few setbacks and difficulties at this stage, (e.g. Huawei was given cold-shoulder in Indian market and was charged by Cisco, etc). It still obtained a good achievement: In 2002, Huawei strengthened input on overseas market further; the number of overseas staff grew to about 2,000. And the key products of Huawei succeeded in penetrating into the European market in large scale. Though from 2001 to 2002, the infrastructure investment of global telecommunications dropped by $50 \%$, Huawei's international sales still increased by 68 percent. Huawei established the joint venture with $3 \mathrm{COM}$ in 2003 to manufacture enterprise data network equipments. In 2004, it set up a joint venture with Siemens to focus on the research, production, sales and services of TD-SCDMA. In 2005, Huawei's overseas sales exceeded domestic market sales for the first time. Accordingly, the Chinese market was reorganized into a China department and became one of the nine regional departments in global market, symbolizing Huawei's transformation from a domestic-market-focused company into a real transnational corporation. Huawei gained even more network projects in Britain, France and Japan in 2005 and 2006, realizing an all-directional growth in both the market share in the developed countries and technology improvements.

\subsubsection{The key risk perception}

(1) Macroscopic risk: The third stage was a turning point for Huawei. At this stage, Huawei shifted from a so called "quantity expansion" to a "quality expansion" and made great progress in both the market shares in developed countries and technology advancement. The policy risk was the key risk at the macroscopic level. As a Chinese old says goes, "a tall tree catches the wind", now Huawei has already established certain international strength, government restrictions of trade and industry of host country all influence its further development. For example, India National Security Department refused one investment plan of 60 million dollars offered by Huawei in August, 2005. In 2006, a GSM mobile network expansion contract valued at 4,800 million dollars of India's biggest telecommunication operator BSNL called for bid, Ericsson and Nokia became the biggest winner. Huawei failed to participate in the competitive bidding because the bid required that $1 / 3$ of the needed equipment must be manufactured in India. On the other hand, because of the end of WTO protection period, changes in government's industry support policy made enterprises face enormous risk. The export rebate rate of electronic information products was changed to $13 \%$ for a period from January to October in 2004. Consequently, 
Chinese firms' export was heavily affected. Chinese government had to raise the rebate rate 17\% in November, 2004.

(2) Industrial risk: The risk at the industrial level is similar to that of in the previous stage, which mainly comes from the competition and technology changes. Since other telecommunication giants have recognized the threat from Huawei at this stage, they took various kinds of ways to compete with Huawei. For example, except Cisco, Huawei is the only company can provide all kinds of serial router and switch solutions, and its average price is lower than that of Cisco by $20 \%$. In 2003, Cisco accused Huawei of infringed some technical patents of it. Though the two parties solved the patent dispute through reconciliation, it was obviously that Cisco's purpose was not only to protect its intellectual property right, but also prevent Huawei's overseas expansion. As to technology change, progresses made in optical communication technology can make the communication capacity improve by $100 \%$ every 9 months. In this course, technological break-through often comes out. Under the environment of technology competition, if a company can not develop new products in time ahead of the market, it will lose the market opportunity. For example, because Bell Laboratory (affiliated to Lucent Company) chipped in the wrong technology, instead of in the promising GSM technology, the performance of Lucent Company declined to an enormous extent when global mobile communication develops at full speed.

(3) Corporate risk: Because Huawei is well on the way to become an outstanding internationalized enterprise, the key risks at the corporate level are decision-making and investment risk besides human resources risk. The telecommunication equipment manufacturing industry is technology-oriented, which means it is also people-oriented. Human resources are what new hi-tech enterprises need to pay close attention to all the times. Because of the uncertainty of technology and research, the investment risk is the key risk at this stage. Once made an erroneous judgment on development trend and invest in technology with small potential, it will cause serious consequences. In 1992, Ren Zhengfei, invested a hundred million RMB yuan to develop the digital C\&C08 switch. It was later proved to be a very smart decision and brought in tremendous profit for Huawei. In another case, Huawei gave up its wireless technology of local call business and received nothing in the PHS market, while its rival, ZTE made a great fortune.

\subsubsection{Risk prevention measures}

At present, the internationalization of Huawei is at the third stage. The risks faced by Huawei interweave with each other, which has brought considerable difficulties to risk prevention. Huawei has taken some measures, but the real 
effects of these measures still needed to be further tested in practice.

The controllable degree of the policy risk of host country is relatively low. If the host country imposes restriction on market entry in order to protect the national industry or information security, foreign enterprises can only choose other countries instead. However, it is a pity to give up such markets of enormous potential as India. Huawei still wants to low down the barrier of the market limit through government public relations or utilize international trade rules. So far, Huawei has not overcome the entry barrier of India and sell products in India mainly through its local agents.

When confronting competition risk and technology risk, an enterprise needs to take initiatives. Because the telecommunication equipment is various in styles, technology innovation is quick, so it is of enormous risk to merge other companies. Hence Huawei has adopts a dynamic alliance strategy and divides it allies into market alliance, technological alliance and standard alliance. For example, Huawei signed a cooperative agreement with 3Com in 2003 to form market alliance. 3Com utilized Huawei's marketing channel and cost advantage, Huawei can sell products bearing the brand of $3 \mathrm{Com}$. Huawei also cooperates or sets up joint research centers with world-class companies ( Such as Intel, Texas Instruments, Freescale Semiconductor, Qualcomm, Infineon, Agere Systems, Microsoft, IBM, Sun Microsystems and HP, etc.) to form technological alliance; In addition, Huawei became a member of 78 International Standards Organization such as ITU, 3GPP, IEEE, IETF, ETSI, OMA, TMF, FSAN and DSLF, etc. Adopting the internationalized standards of these organizations, Huawei can cooperate with its upstream and downstream partners better and reduce the risk of $R \& D$. These alliances played an essential role on preventing and dissolving competition and technology risk. For example, 3COM Company not only cooperates with Huawei in technology and market, it also offered enormous support when Cisco sued Huawei.

Huawei has both successful and failed experience on the investment decision. The biggest risk Huawei has engaged in so far is the research of $3 \mathrm{G}$. Ren Zhengfei put hundreds of millions of money and $1 / 3$ of its research personnel into the research of WCDMA, while paid little attention to other standards as TD-SCDMA. But Chinese government has repeatedly postponed granting the needed $3 \mathrm{G}$ license to the four major domestic telecommunications operators, it made the investment risk increase dramatically. In order to disperse the risk, Huawei set up a joint venture with Siemens which focused on the research of TD-SCDMA for China market in 2004. In order to prevent product decision risk, Huawei carried out Integrated Product Development (IPD) designed by IBM. IPD is a kind of idea and method concerning product development which covers the whole course from the products concept development to the products 
introduction. It puts emphasis on the market demand, structures, the advantage of product quality, cost and service in the product design and manages product development as an investment to guarantee the investment return.

The above is summarized as Fig. 4.

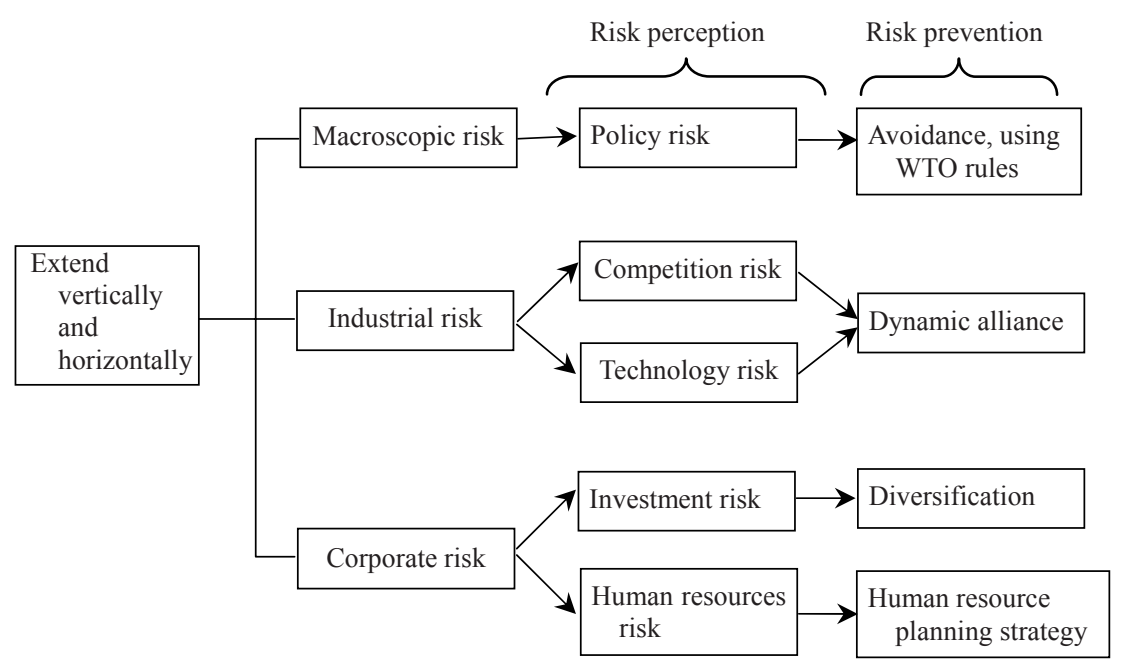

Fig. 5 Risk perception and prevention at the stage of "all-round expansion"

\section{Summaries}

\subsection{Practical suggestions}

This study synthesizes Miller's international risk theory with Johanson's progressive internationalization theory and attempts to structure the integrated model of internationalization entry degree and integrated risk perception (Fig. 2). This has put forward a new research path in the research field of internationalization and it is also the study foundation of "the interaction of risk management and the strategic decision". Meanwhile, this paper utilizes case study to prove to the suitability of the model. The constantly changeable key risks of Huawei's internationalization process can be perceived from the three levels under the framework construct in this paper. Since the hi-tech firms in our country are highly similar at the technological level of products, international competition degree and inside management, the model we construct is suitable for risk management of other similar hi-tech enterprises. This paper utilizes the strict case study approach to observe representative enterprises from the micro aspect. And it has offered a thinking platform for innovative discussion on the 
risk management of enterprises' internationalization on the basis of the extension of foreign theory and Chinese enterprises' internationalization practice.

Practical suggestions include:

(1) The new hi-tech enterprises of developing countries can succeed in internationalization too. Wells (1983) proposed the theory of Small Scale Technology after analyzed the competition advantage of developing country's FDI in the book Third World Multinationals(MIT Press); Lall(1983) proposed the theory of Localized Technological Change in his book The new multinationals: The spread of Third World enterprises. Both the two authors proved the possibility of developing country's enterprises' internationalization from the perspectives of technology and comparative advantage, respectively. Huawei's success confirms these statements further from a practical view. So, qualified Chinese hi-tech enterprises should establish the confidence and start internalization when possible.

(2) At the preliminary stage of internationalization, an enterprise should choose the correct target market and entry mode according to its strength and competition characteristics. Specifically, at the first step of internationalization, the enterprise had better enter the most suitable market according to the identification of the key risks and adjust strategy step by step along with the progress of its internationalization. For example, for those small and medium sized enterprises that lacked the necessary experiences in international business, the safe way to enter a foreign market is to choose those countries with less harsh competition through foreign trade. With the accumulation of internationalization experience and competition strength, they can choose the best scheme to enter into the international market in accordance with their own strategic requirements and risk factors. Huawei's early success lies in the selection of entering in such countries in Asia, Latin America, etc. Then after accumulated technology and internationalization experience to a certain extent, it entered such developed countries as America and Europe.

(3) Different internationalization stages correspond with different key risks, but some risks are throughout the whole process. This means hi-tech enterprises should not merely pay attention to the perception of the key risk at the present stage, but also pay close attention to the potential risks extending along with the vertical and horizontal axes (technology and entry barrier), so they can carry on long-term strategic planning. As to hi-tech enterprise, technology and human resources risk are long-term risks. For instance, Huawei adopts encouraging policy from cultural spirit to the material prize and strategic talent's storage system at different stages along its development to deal with the human resources risk.

(4) To assist firms in fighting against different risks enterprises faced at 
different internationalization stage, government should offer the macroscopic policy guidance, perfect the function of the policies and regulations that support internationalization, and support the risk management of the hi-tech enterprises in a planned way. As above, that Huawei can obtain technology break-through is closely related to the support it received from the government. Chinese government should perfect its economic policy, accelerate making and perfecting the regulation system of overseas investment such as "law of overseas investment of Chinese enterprise", promote macroscopic management policy of overseas investment further, such as the approval system, distribution and personnel system, etc., adopt such proper preferential support policy to internationalizing business as the preferential bank loan, import and export credit, financial discount, export tax rebates, etc. For example, if enterprises enter the international market by means of foreign trading, government needs to offer support to them once the enterprises confront anti-dumping investigation in host countries (see Provisions on Responding to Actions of Antidumping of Export Products for details). Also, other regulations, such as the Suggestion on Taking Measures to Encourage Expanding Foreign Export, have created a more favorable environment for domestic firms to participate in the international competition. The government can also set up foreign export fund to promote more key commodities' export and improve hi-tech enterprises' financing ability by offering special financial guarantee and various short-term loans.

\subsection{Limitations}

First of all, though the single case study approach we used in this research helps deepen our study on complicated phenomenon. However, whether our study conclusions can be applied to other types of enterprises remains untested. Thus, one direction for future research in this field is to use other research methods, such as, the cross-case analysis approach (Eisenhardt, 1989), to further test our conclusions. Second, the division of Huawei's internationalization process and risk analysis frame of this study based on extension of classical theory, the validity of the model still awaits verification by large sample tests. Finally, our analysis of Huawei's risk perception and prevention was mainly based on Huawei's historical experiences and statistics. A more accurate study should address deeper risks Huawei will confront in the future.

Acknowledgements This study is supported by the National Natural Science Foundation of China (Grant No. 70572081). 


\section{References}

Agarwal S, Ramaswami S N(1992). Choice of foreign market entry mode: Impact of ownership, location, and internationalization factors. Journal of International Business Studies, 23: 1-27

Alan C S(2002). Foundations of Multinational Financial Management. Beijing: Citic publishing House

Anderson E, Gatignon H(1986). Modes of foreign entry: A transaction cost analysis and propositions. Journal of International Business Studies, 17(3): 1-26

Beamish P, Banks J(1987). Equity joint-ventures and the theory of the MNE. Journal of International Business Studies, 19(2): 1-16

Brouthers K D(1995). The influence of international risk on entry mode selection in the computer software industry. Managmente International Review. 35(1): 7-25

Brouthers K D, Brouthers L E, Werner S(1996). Dunning's eclectic theory and the smaller firm: The impact of ownership and locational advantages on the choice of entry-modes in the computer software industry. International Business Review, 5(4): 377-394

Brouthers K D, Brouthers L E, Werner S(2002). Industrial sector perceived environmental uncertainty and entry mode strategy. Journal of Business Research, 55: 498-499

Carlson S(1975). How foreign is foreign trade? Working Paper. The University of Uppsala

Cheng Dongsheng, Liu Lili(2004). The truth of Huawei. Beijing: Contemporary Chinese Press (in Chinese)

Chu W, Anderson E(1992). Capturing ordinal properties of categorical dependent variables: A review with application to modes of foreign entry. International Journal of Research in Marketing, (9): 149-160

Du Zhou(2006). In India and Latin America-The international variations of ZTE and Huawei. IT Time Weekly, (11) (in Chinese)

Dunning J H(1988). The eclectic paradigm of international production: A restatement and some possible extensions. Journal of International Business Studies, 19(1): 1-31

Eisenhardt K M(1989). Building theories from case study research. Academy of Management Review, 14: 532-550

Gatignon H, Anderson E(1988). The multinational corporation's degree of control over foreign subsidiaries: An empirical test of a transaction cost explanation. Journal of Law, Economics and Organization, 4(2): 305-336

Huang Weiwei, Wu Chunbo(2001). Go out of Chaos. Beijing: Post\&Telecom Press (in Chinese)

Johanson J, Vahlne J-E(1990). The mechanism of internationalization. International Marketing Review, 7(4): 11-24

Kim W C, Hwang P(1992). Global strategy and multinationals' entry mode choice, Journal of International Business Studies, 23(1): 29-53

Kogut B, Singh H(1988). The effect of national culture on the choice of entry mode. Journal of International Business Studies, (19): 411-432

Kwon Y-C, Konopa L J(1993). Impact of host country market characteristics on the choice of foreign market entry mode. International Marketing Review, 10(2)

Lall S(1983). The new multinationals: The spread of the third world enterprises. Chichester; NY: Wiley

Liu Qicheng(2004). The ten year hardship of Huawei's internationalization. China Small-medium Enterprise, (12) (in Chinese) 
Martin A D, Mauer L J(2003). Transaction versus economic exposure: Which has greater cash flow consequences? International Review of Economics and Finance, (12): 438

Miller K D(1992). A framework for integrated risk management in international business. Journal of International Business Studies. (2): 311-331

Miller K D(1993). Industry and country effects on managers' perceptions of environmental uncertainties. Journal of International Business Studies, 24: 693-714

Reid D M, DeMartino R, Zyglidopoulos S C(2005). The internationalization journey of a high-tech cluster. Thunderbird International Business Review, 47(5): 529-554

Root F R(1994). Entry Strategies for International Markets. New York: Lexington Books

Shan Yonggui(2006). The way of Huawei's internationalization. Management \& Technolosy of SME (in Chinese), 2006-04-008

Sun Haifa, Liu Yunguo, Fang Lin(2004). Theoretic foundation and operational procedure of case study. Science Research Management (in Chinese), 2004-02-18

Sutcliffe K M, Zaheer A(1998). Uncertainty in the transaction environment: An empirical test. Strategic Management Journal, 19(1): 1-23

Tang Shengping (2004). Go Out of Huawei. Beijing: China Social Sciences Press (in Chinese)

Wells L T(1983).The Third World Multinationals: The Rise of Foreign Investment from Developing Countries. Cambridge, MA: MIT Press

Wu Jianguo, Ji Yongqin(2006). The World of Huawei. Beijing: CITIC Press (in Chinese)

Xie Jianping(2000), Modern Investment Study: Analysis and Management. Taipei: Zhisheng Press (in Chinese)

$\mathrm{Xu}$ Hui(2006).The International Risk Management. Beijing: University of International Business and Economics Press (in Chinese)

Yin R K(1989). Case Study Research: Design and Methods. Newbury Park, CA: Sage

Zhang Guanjing(2007). Four faces of Huawei-Overseas Founder analyses Huawei in Its Internationalization. Guangzhou: Guangdong Economy Press (in Chinese)

Zhang Lei (2006). Research for Internationalization Development Strategy in China Enterprise. $\mathrm{Ph} . \mathrm{D}$ dissertation of Xiamen University (in Chinese)

Zhang Lihua, Liu Songbo(2006). From cross-case study to expand the explanation strength of contemporary theory - The second management case study seminar of China. Management World, (12) (in Chinese)

Zhao Xin(2007). How to construct the strategic human resources plan-See from Huawei. Entrepreneurs' World, (4) (in Chinese) 